DOI: 10.12731/2227-930X-2019-1-7-25 УДК 657

\title{
СОВЕРШЕНСТВОВАНИЕ ОПЕРАТИВНОГО ПЛАНИРОВАНИЯ ПЕРЕВОЗОК ГРУЗОВ В АВТОТРАНСПОРТНЫХ СИСТЕМАХ: НОВЫЙ ПОДХОД
}

\section{Мочалин М.С., Кухарев Е.А.}

В статье рассматривается вопрос совершенствования решения задачи маршрутизации в спроектированных автотранспортных системах доставки грузов. Авторы делают вывод о том, что ошибки при оперативном планировании перевозок грузов получаются не при решении транспортной задачи, а в результате неправильной расшифровки полученного решения.

Цель - оптимизация планирования перевозок грузов автотранспортом за счет совершенствования научных подходов в расшифровке результатов решения задач маршрутизации.

Метод или методология проведения работы: при написании данной статьи использовались методы системного, структурного, сравнительного анализа и экономико-математическое моделирование. При проведении расчетов применяются модели транспортных систем нижнего уровня, позволяющие рассчитать оперативный план перевозок грузов автомобилями в транспортных системах.

Результаты: выявлено, что при решении задачи маршрутизациии в городских условиях эксплуатации, проектируются транспортные системы нижнего уровня, причем всего спектра: микро, особо малье, малье, средние, и совокупности средних. При этом совершенствуется научный подход к проектированию транспортных систем нижнего уровня, предложенный профессором В.И. Николиным. Уточняется понимание процесса проектирования, состоящее в том, что совершенствование подхода кидентификации транспортных систем, основанного на классификаци- 
International Journal of Advanced Studies, Vol. 9, No 1, 2019

онных признаках, позволяет правильно организовать и повыссить производительность транспортных систем.

Область применения результатов: предлагаемый новылй подход оперативного планирования грузовых автомобильных перевозок дает возможность установить научно обоснованное плановое задание для автотранспорта, пунктов погрузки и разгрузки и системы управления транспортных систем.

Ключевые слова: экономико-математические методы; моделирование; оперативное планирование; перевозка грузов; автомобильный транспорт.

\section{PERFECTION OF OPERATIONAL PLANNING OF CARGO TRANSPORTATION IN MOTOR TRANSPORT SYSTEMS: A NEW APPROACH}

\section{Mochalin M.S., Kukharev E.A.}

The article discusses the issue of improving the solution to the problem of routing in the designed road haulage delivery systems. The authors conclude that the errors in the operational planning of the transportation of goods are not obtained when solving the transportation problem, but as a result of the incorrect decoding of the obtained solution.

Purpose. Optimization of cargo transportation planning by improving scientific approaches to deciphering the results of solving routing problems.

Methodology in article the methods of systemic, structural, comparative analysis and economic-mathematical modeling were used. In the course of calculations, models of lower-level transport systems are used, allowing to calculate the operational plan for the carriage of goods by vehicles in transport systems.

Results. It was revealed that when solving the problem of routing in urban conditions, transport systems of the lower level are being designed, and the whole spectrum: micro, especially small, small, medi- 
um, and medium sets. At the same time, the scientific approach to the design of lower-level transport systems, proposed by Professor V.I. Nikolin. It clarifies the understanding of the design process, which consists in the fact that the improvement of the approach to the identification of transport systems, based on classification criteria, allows you to properly organize and improve the performance of transport systems.

Practical implications the proposed new approach to operational planning of road freight transport makes it possible to establish a scientifically based planning task for vehicles, loading and unloading points and the control systems of transport systems.

Keywords: economic and mathematical methods; modeling; operational planning; transportation of goods; road transport.

\section{Введение}

Цель работы: оптимизация планирования перевозок грузов автотранспортом за счет совершенствования научных подходов в расшифровке результатов решения задач маршрутизации. Предмет исследования: оперативное (сменно-суточное) планирование перевозок грузов автомобилями в автотранспортных системах. Объект исследования: автотранспортные системы доставки грузов, проектируемые с помощью экономико-математических методов (ЭММ).

В настоящее время планирование и управление деятельностью грузового автомобильного транспорта невозможно без применения экономико-математических методов, позволяющих в значительной мере повысить эффективность использование подвижного состава и производительность труда.

Одной из важных задач управления на транспорте, которую необходимо решать, является задача проектирования оптимальных маршрутов доставки грузов рациональным типом транспортных средств. В работах ряда специалистов в области применения ЭММ на автомобильном транспорте Б.Л. Геронимус, А.П. Кожин, В.А. Бабарыкина отмечается, что при решении задачи маршрутизации получаются маятниковые маршруты с обратным не груже- 
ным пробегом и кольцевые маршруты помашинных отправок [2, $11,12]$. Однако, как показал анализ результатов исследования проведенные в СибАДИ, это оказалось далеко не так. При расшифровке решения задачи маршрутизации упущен немаловажный аспект, состоящий в том, что:

1) Почему не проектируются маятниковые маршруты с обратным груженым пробегом различного типа?

2) Некоторые маршруты начинаются либо заканчиваются в одном и том же грузовом пункте. Это указывает на то, что в данном случае мы имеем дело не с изолированными маятниковыми и кольцевыми маршрутами, а с более сложной организационной системой маршрутов - с радиальными.

В работе [3] отмечается, что радиальные маршруты имеют свои характерные особенности протекания транспортного процесса и требуют применения соответствующего математического аппарата в определении показателей работы подвижного состава.

3) Другой ошибкой при решении задачи маршрутизации является утверждение в работе [2] “... что, при решении транспортной задачи в городских условиях эксплуатации является получение совокупности средних автотранспортных систем перевозок грузов помашинными отправками, а не маятниковых кольцевых маршрутов или автотранспортных систем меньшей сложности”.

При анализе многочисленных результатов моделирования транспортных процессов, проведенных на примере перевозок массовых грузов помашинными отправками, доказано, что могут проектироваться изолированные в пространстве и времени транспортные системы меньшей сложности, наряду с совокупностью средних систем доставки грузов. Полученный результат вносит новое научное представление о полученных результатах маршрутизации перевозок грузов в транспортных системах. Он позволяет ответить на вопрос: как проектируются транспортные системы, и какие виды совокупности их могут быть?

В работе [1] профессор Николин В.И. утверждал, что грузовые автомобили осуществляют работу не изолировано, а в определенной 
транспортной системе. Это подтверждается практикой перевозочной деятельностью транспортных предприятий, которая осуществляется одной или нескольких транспортных систем. В связи с этим возникла необходимость уточнения классификации транспортных систем, и ввести понятие «интегрированные транспортные системы». Интегрированные транспортные системы - представляют собой совокупности транспортных систем различного вида, где планирование и управление которыми объединены в единую систему. Интеграция транспортных систем в одну осуществляется на основе достижения единой цели, результатов, причем не важно, интегрируются системы по отраслевому принципу или корпоративному принципу, по грузу или принадлежности автомобилей, применяются ли положения логистики при этом или нет. Примером на практике можно наблюдать интегрированную транспортную систему осуществляющую перевозку грузов в эшелонированных и комплексных цепях поставок в городских условиях эксплуатации и в междугороднем сообщении с применением юнимодальных и мультимодальных способов перевозки. Интегрированная транспортная система состоит из систем одна (несколько) микро, особо малая, малая, средняя, совокупность средних, большая, развозочно-сборных систем всех видов, из различного их сочетания и количества.

Не учет данных особенностей на практике и применение традиционного математического аппарата, изложенного в работе [4], может приводить к существенным несоответствиям расчетной и фактической результатам функционирования транспортных систем.

Другим сдерживающим аспектом применения ЭММ, является процедура оптимизации работы автомобилей в спроектированных транспортных системах и переключения автомобиля задействованного в одной транспортной системе в другую. В работе профессора Кожина А.П. [4] приводится процедура такого переключения, однако она не в полной мере учитывает особенности протекания транспортного процесса на маршрутах, по которым функционирует более одного автомобиля. При переезде автомобиля на такой маршрут может оказаться, что большую часть остатка времени на 
данном маршруте он проведет в ожидании выполнения погрузочно-разгрузочных работ уже работающих там транспортных средств и не выполнит запланированный объем транспортной работы. Это в большей мере проявляется в насыщенных автомобилями транспортных системах. Переезд автомобиля в такую транспортную систему приведет к появлению у всех работающих автомобилей времени ожидания погрузочно-разгрузочных работ, а следовательно возможности не выполнения планового задания за время в наряде.

Данный аспект отмечается в работах А. Кофмана и А. АнриЛабрардера $[6,7,8]$, которые на основе положений теории исследования операций выявляли законы появления очереди. Они отмечали, что «для появления очереди достаточно, чтобы поступления требований происходило в нерегулярные промежутки времени. Она так же может возникнуть при постоянном времени обслуживания и поступлении требований через равные промежутки, если продолжительность обслуживания превышает интервал времени, разделяющий моменты прибытия». Тем самым было отмечена зависимость образования очереди от соотношения интервала прибытия автомобилей и ритма их обслуживания в грузовом пункте.

В работе [7] отмечается, что при решении задачи маршрутизации помашинных отправок получаются не маршруты, а транспортные системы расчет транспортных ресурсов в которых, необходимо вести с помощью соответствующих математических моделей.

Из вышесказанного следует, необходимо разработать такую процедуру оперативного планирования, которая включала бы в себя правильную расшифровку решения задачи маршрутизации.

\section{Материалы и методы}

Для условий сопоставимости полученных результатов с ранее полученными результатами, рассмотрим пример, представленный в работе 3. Необходимо осуществить перевозку транспортно-однородных грузов от 8 грузоотправителей 12 грузополучателям. Городские условия перевозки: Матрица кратчайших расстояний транспортной системы известна. Перевозку грузов осуществляет автомобиль КА- 
MA35511, qн $=7$ т, tпр $=10$ мин., $\gamma \mathrm{c}=1, \mathrm{TH}_{\mathrm{H}}=10$ часов. Количество постов разгрузки/погрузки в грузовых пунктах = 1. Объемы производства и объемы потребления транспортно-однородного груза известны. Необходимо составить оптимальный план перевозок грузов автомобильным транспортом.

Расчеты проводятся в соответствии с методикой СибАДИ, представленной в работе 3. Этапы решения транспортной задачи представлены на рисунке 1. На первом - этапе выявляют встречные грузовые потоки и формируют ма-

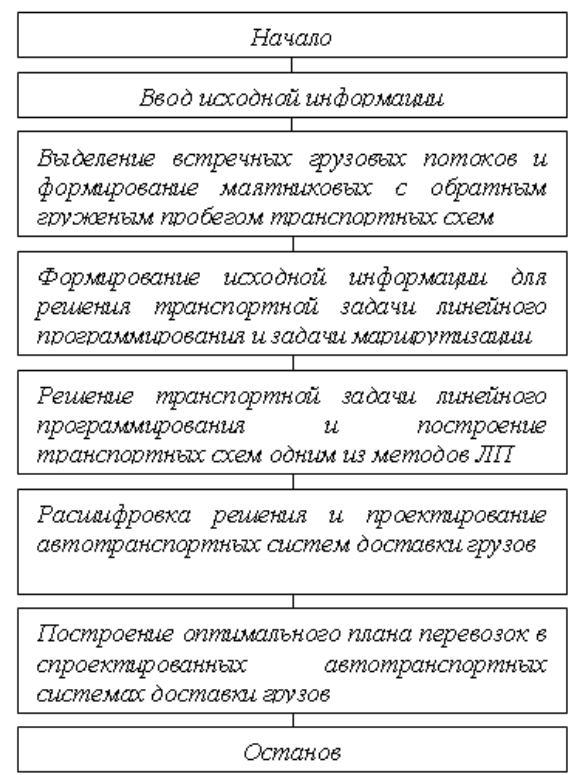

Рис. 1. Этапы рещения транспортной задачи ятниковые маршруты с обратным груженым пробегом. На втором этапе - скорректированный план перевозок является исходной информацией для решения транспортной задачи (решение задачи оптимального закрепления потребителей за поставщиками, одним из известных методов линейного программирования) $[1,2,3]$. На третьем этапе - решение задачи оптимизации порожних пробегов автомобилей с помощью известных методов математического моделирования. На четвертом этапе - организация транспортных схем перевозок грузов (маятниковые, кольцевые, радиальные), например методом таблиц связей. Решение задачи идентификации транспортных систем доставки грузов (микро, особо малые, малые, средние и совокупность средних). На пятом этапе - расшифровка решения задачи маршрутизации. На основании расчетов показателей результатов функционирования спроектированных транспортных схем. 


\section{Результаты}

По результатам расчетов по методике СибАДИ (см. таблица 1), спроектированы 12 транспортных схем перевозки грузов. 6 схем, ветви которых соответствуют по конфигурации маятниковому маршруту с обратным не груженым пробегом и 5 схем, ветви которых соответствуют по конфигурации кольцевому маршруту помашинных отправок. При проведении процедуры идентификации транспортных систем изложенной в работе [1] , эти 11 транспортные схемы синтезируются в автотранспортные системы доставки грузов.

Для выполнения планового объема перевозок необходимо привлечь 33 автомобиля, которые совершат общий пробег $\mathrm{L}=5125$ км.

Однако, некоторые автомобили в транспортных системах работают неполное время в наряде. Например, в табл. 1: первый маршрут, второй автомобиль Тф $=0,95$ ч.; четвертый маршрут, второй автомобиль Тф = 2,54 ч.; седьмой маршрут, шестой автомобиль Тф $=2.02$ ч.; восьмой маршрут Тф = 2,83 ч., и т.д.

Для разработки интенсивного сменно-суточного плана перевозок необходимо оптимизировать работу по критерию Тфі $\rightarrow$ max. При этом необходимо рассмотреть возможность переезда автомобиля из одной транспортной системы в другую. Результаты расчетов представлены в таблице 2. В итоге необходимо 27 автомобилей, что в числовом выражении потребность сократилась на 6 единиц. Общий пробег составит L = 4795 км., сократится на 330 км. (7\%).

Таблицуа 1.

Результаты расчета потребности в автомобилях по методике СибАДИ

\begin{tabular}{|c|c|c|c|c|c|c|c|c|c|c|}
\hline $\begin{array}{c}\text { Номер } \\
\text { марш- } \\
\text { рута }\end{array}$ & $\begin{array}{c}\text { Шифр } \\
\text { транспортной } \\
\text { схемы перевозок }\end{array}$ & $\begin{array}{l}\text { № } \\
\text { авт. }\end{array}$ & $\begin{array}{c}\text { Qпл, } \\
\text { т }\end{array}$ & $\begin{array}{c}\text { Qi, } \\
\text { T }\end{array}$ & $\begin{array}{l}Z^{\text {лл }}, \\
\text { езд }\end{array}$ & $\begin{array}{l}\text { Zoi, } \\
\text { езд }\end{array}$ & $\underset{\mathrm{Mi}}{\mathrm{T}_{\mathrm{Mi}}}$ & $\begin{array}{c}\text { Tфi, } \\
\text { ч }\end{array}$ & $\begin{array}{c}\mathrm{DT}_{\mathrm{H}}{ }_{\mathrm{Y}} \mathbf{Y} \\
\end{array}$ & $\begin{array}{c}\text { LM, } \\
\text { км }\end{array}$ \\
\hline 1 & 4 & $\begin{array}{l}1 \\
2\end{array}$ & 200 & $\begin{array}{c}189 \\
11\end{array}$ & 29 & $\begin{array}{c}27 \\
2\end{array}$ & $\begin{array}{l}10,00 \\
10,00\end{array}$ & $\begin{array}{l}9,87 \\
0,95\end{array}$ & $\begin{array}{l}0,13 \\
9,75\end{array}$ & $\begin{array}{c}194 \\
38\end{array}$ \\
\hline 2 & А2Б2-Б2А2 & 1 & 150 & 150 & 22 & 22 & 10,00 & 7,65 & 2,35 & 186 \\
\hline 3 & А5Б6 & 1 & 100 & 100 & 14 & 14 & 10,00 & 8,30 & 1,70 & 177 \\
\hline 4 & А4Б8-Б8А4 & $\begin{array}{l}1 \\
2\end{array}$ & 200 & $\begin{array}{c}154 \\
46\end{array}$ & 29 & $\begin{array}{c}22 \\
7\end{array}$ & $\begin{array}{l}10,00 \\
10,00\end{array}$ & $\begin{array}{l}9,74 \\
2,54\end{array}$ & $\begin{array}{l}0,26 \\
7,46\end{array}$ & $\begin{array}{c}218 \\
90\end{array}$ \\
\hline
\end{tabular}


Окончание табл. 1.

\begin{tabular}{|c|c|c|c|c|c|c|c|c|c|c|}
\hline 5 & А8Б11-Б11А8 & $\begin{array}{l}1 \\
2 \\
\end{array}$ & 50 & $\begin{array}{l}28 \\
21\end{array}$ & 7 & $\begin{array}{l}4 \\
3 \\
\end{array}$ & $\begin{array}{l}10,00 \\
10,00 \\
\end{array}$ & $\begin{array}{l}8,36 \\
6,31 \\
\end{array}$ & $\begin{array}{l}0,52 \\
2,57 \\
\end{array}$ & $\begin{array}{l}178 \\
130 \\
\end{array}$ \\
\hline 6 & А7Б12-Б12А7 & 1 & 150 & 150 & 22 & 22 & 10,00 & 9,29 & 0,71 & 180 \\
\hline 7 & 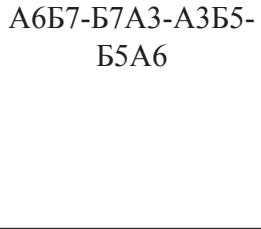 & $\begin{array}{l}1 \\
2 \\
3 \\
4 \\
5 \\
6\end{array}$ & 150 & $\begin{array}{l}28 \\
28 \\
28 \\
28 \\
28 \\
10\end{array}$ & 22 & $\begin{array}{l}4 \\
4 \\
4 \\
4 \\
4 \\
2\end{array}$ & $\begin{array}{c}10,00 \\
10,00 \\
9,92 \\
9,92 \\
9,84 \\
9,84\end{array}$ & $\begin{array}{l}8,56 \\
8,56 \\
8,56 \\
8,56 \\
8,56 \\
2,02\end{array}$ & $\begin{array}{l}1,44 \\
1,44 \\
1,36 \\
1,36 \\
1,28 \\
7,82\end{array}$ & $\begin{array}{c}200 \\
200 \\
200 \\
200 \\
200 \\
56\end{array}$ \\
\hline 8 & $\begin{array}{c}\text { А8Б11-Б11А4- } \\
\text { А4Б8-Б8А3-А3Б3 } \\
- \text { Б3А } 8\end{array}$ & $\begin{array}{l}1 \\
2 \\
3\end{array}$ & 50 & $\begin{array}{c}21 \\
21 \\
8\end{array}$ & 7 & $\begin{array}{l}3 \\
3 \\
1\end{array}$ & $\begin{array}{c}10,00 \\
10,00 \\
9,92\end{array}$ & $\begin{array}{l}8,65 \\
8,65 \\
2,83\end{array}$ & $\begin{array}{l}2,35 \\
2,35 \\
7,09\end{array}$ & $\begin{array}{c}190 \\
190 \\
64\end{array}$ \\
\hline 9 & $\begin{array}{c}\text { А } 8 \text { Б10-Б10А5- } \\
\text { А5Б9-Б9А2-А2Б4- } \\
\text { Б4А3-АЗБ5-Б5А }\end{array}$ & $\begin{array}{l}1 \\
2 \\
3 \\
4 \\
5 \\
6 \\
7\end{array}$ & 100 & $\begin{array}{l}14 \\
14 \\
14 \\
14 \\
14 \\
15 \\
15\end{array}$ & 14 & $\begin{array}{l}2 \\
2 \\
2 \\
2 \\
2 \\
2 \\
2\end{array}$ & $\begin{array}{c}10,00 \\
10,00 \\
9,92 \\
9,92 \\
9,84 \\
9,84 \\
9,76\end{array}$ & $\begin{array}{l}7,12 \\
7,12 \\
7,12 \\
7,12 \\
7,12 \\
7,12 \\
7,12\end{array}$ & $\begin{array}{l}2,88 \\
2,88 \\
2,80 \\
2,80 \\
2,72 \\
2,72 \\
2,64\end{array}$ & $\begin{array}{l}162 \\
162 \\
162 \\
162 \\
162 \\
162 \\
162 \\
\end{array}$ \\
\hline 10 & $\begin{array}{c}\text { А5Б9-Б9А2-А2Б2- } \\
\text { Б2А7-А7Б11- } \\
\text { Б11А5 }\end{array}$ & $\begin{array}{l}1 \\
2\end{array}$ & 25 & $\begin{array}{l}14 \\
11\end{array}$ & 4 & $\begin{array}{l}2 \\
2\end{array}$ & $\begin{array}{l}10,00 \\
10,00\end{array}$ & $\begin{array}{l}6,54 \\
6 ., 54\end{array}$ & $\begin{array}{l}3,46 \\
3,46\end{array}$ & $\begin{array}{l}170 \\
170\end{array}$ \\
\hline 11 & $\begin{array}{c}\text { А } 8 \text { Б10-Б10А5- } \\
\text { А5Б7-Б7А3-А3Б3- } \\
\text { Б3А } 8\end{array}$ & $\begin{array}{l}1 \\
2\end{array}$ & 25 & $\begin{array}{c}21 \\
4\end{array}$ & 4 & $\begin{array}{l}3 \\
1\end{array}$ & $\begin{array}{l}10,00 \\
10,00\end{array}$ & $\begin{array}{l}9,37 \\
3,31\end{array}$ & $\begin{array}{l}0,63 \\
6,69\end{array}$ & $\begin{array}{c}208 \\
68\end{array}$ \\
\hline 12 & $\begin{array}{c}\text { А8Б10-Б10А5- } \\
\text { А5Б9-Б9А2-А2Б2- } \\
\text { Б2А7-А7Б11- } \\
\text { Б11А4-А4Б7- } \\
\text { Б7А3-А3Б3-Б3А8 }\end{array}$ & $\begin{array}{l}1 \\
2 \\
3 \\
4\end{array}$ & 25 & $\begin{array}{l}7 \\
7 \\
7 \\
4\end{array}$ & 4 & $\begin{array}{l}1 \\
1 \\
1 \\
1\end{array}$ & $\begin{array}{l}9,44 \\
9,44 \\
9,36 \\
9,36\end{array}$ & $\begin{array}{l}5,62 \\
5,62 \\
5,62 \\
5,62\end{array}$ & $\begin{array}{l}4,38 \\
4,38 \\
4,30 \\
4,30\end{array}$ & $\begin{array}{l}121 \\
121 \\
121 \\
121\end{array}$ \\
\hline
\end{tabular}

Qпл - план объема перевозок.

Qi - фактический объем перевозок і-го автомобиля за смену.

Zлл - плановое количество ездок совершаемым автомобилем за смену.

Zoi - фактическое количество ездок совершаемым автомобилем за смену.

Тмі-плановое время на маршруте с учетом порядкового выхода автомобиля на линию.

Тфі - фактическое время отработанного автомобиля на і-ом маршруте.

DTHф - остаток времени на маршруте і-го автомобиля.

LM - пробег автомобиля на маршруте.

А - грузоотправитель.

Б - грузополучатель. 


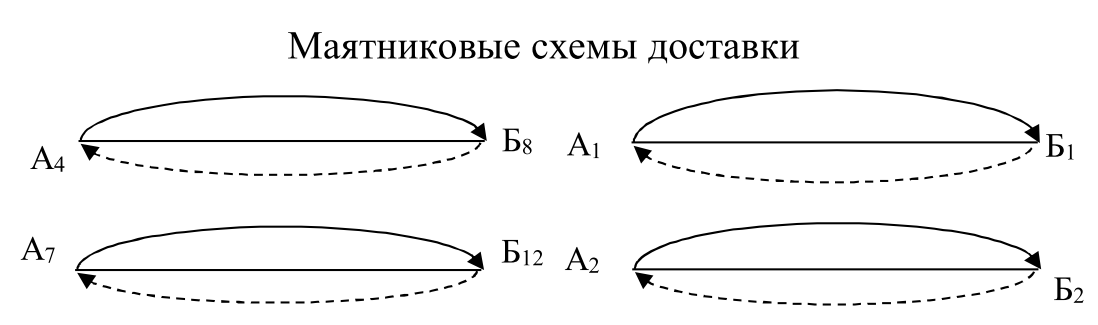

Кольцевая схема доставки грузов

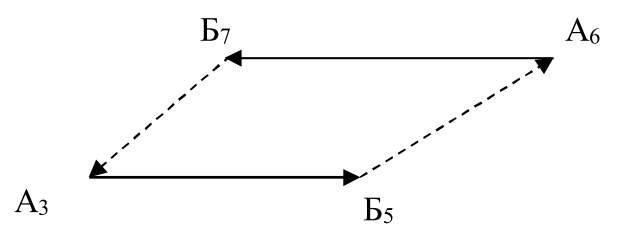

Радиальные схемы доставки грузов

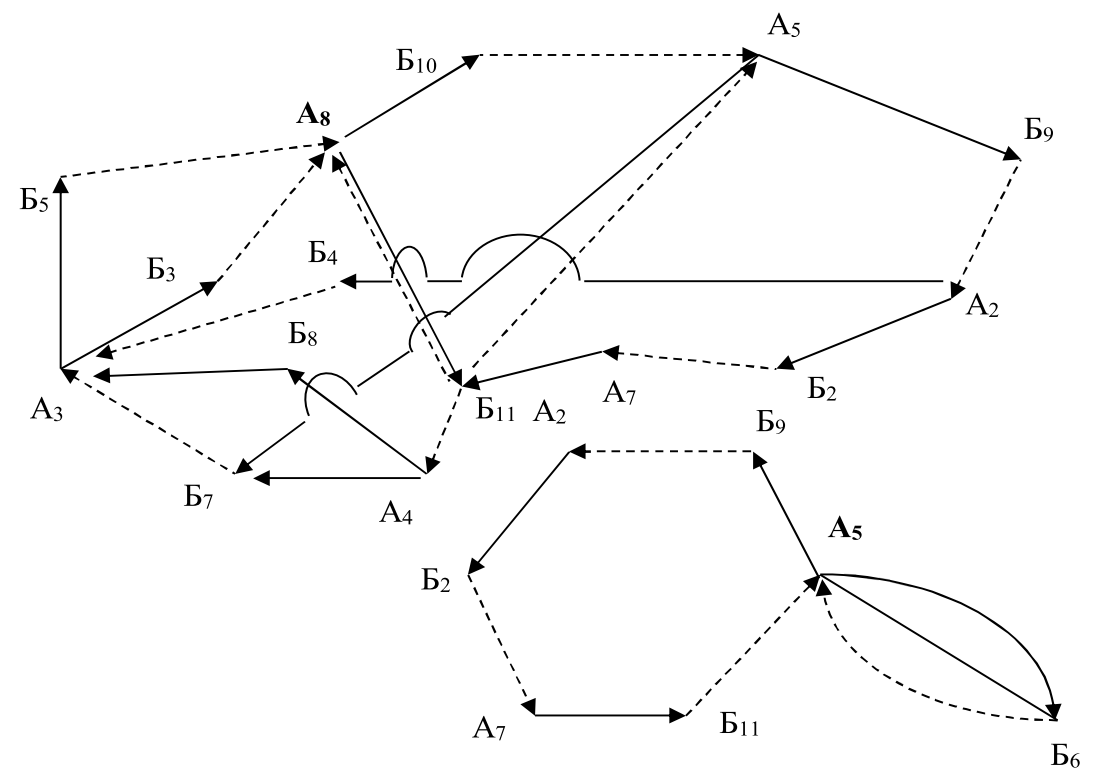

Рис. 1. Транспортные схемы доставки грузов, спроектированные по методике СибАДИ:

$\longrightarrow$ - пробег с грузом; $----------\rightarrow$ пробег без груза. 


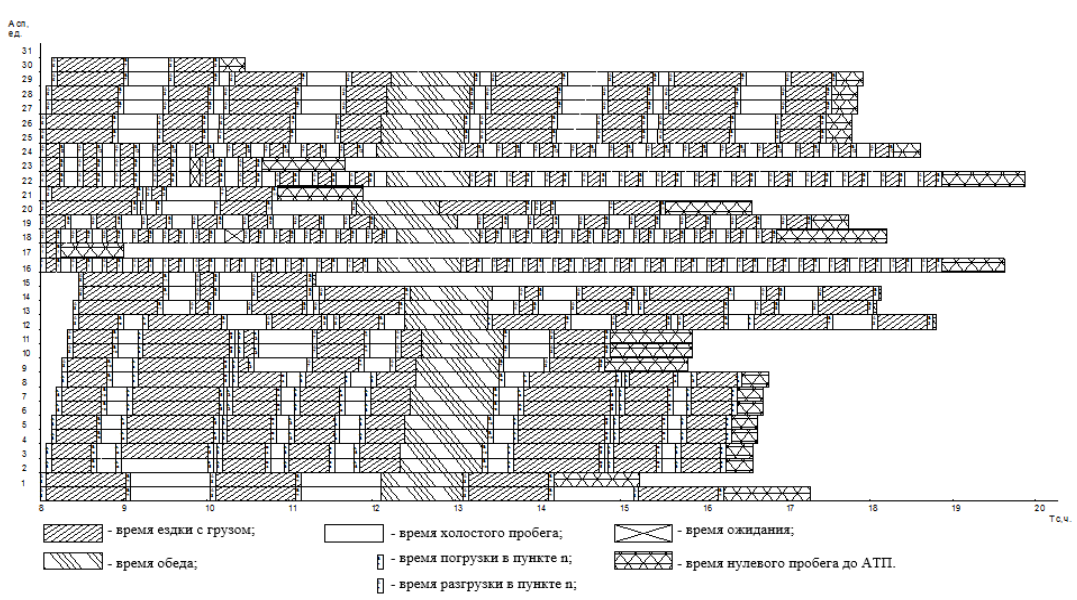

Рис. 3. График работы автомобилей, построенной по методике СибАДИ

Таблицуа 2.

Результаты расчета потребности в автомобилях по предложенной методике

\begin{tabular}{|c|c|c|c|c|c|c|c|c|c|c|c|c|}
\hline 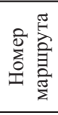 & $\begin{array}{c}\text { Шифр } \\
\text { марш- } \\
\text { рута }\end{array}$ & $\begin{array}{l}\text { № } \\
\text { aBT }\end{array}$ & $\begin{array}{c}\text { to, } \\
\text { ч }\end{array}$ & $\begin{array}{c}\mathrm{Q}_{\text {Пл}}, \\
\mathrm{T}\end{array}$ & $\begin{array}{l}\text { Qi, } \\
\text { T }\end{array}$ & $\begin{array}{c}Z^{\text {Пл }} \\
\text { ед }\end{array}$ & $\begin{array}{l}Z^{\mathrm{B}}, \\
\text { ед }\end{array}$ & $\begin{array}{c}Z^{\Phi}, \\
\text { ед }\end{array}$ & $\begin{array}{c}\mathrm{TM}_{\mathrm{i}} \\
\mathrm{\varphi}\end{array}$ & $\begin{array}{c}\mathrm{T} \phi_{\mathrm{i}} \\
ч\end{array}$ & $\underset{ч}{\mathrm{DT}} \phi_{\mathrm{I}}$ & $\begin{array}{l}\text { LM, } \\
\text { Kм }\end{array}$ \\
\hline \multirow[t]{3}{*}{1} & \multirow{3}{*}{$\begin{array}{l}\text { А1Б1- } \\
\text { Б1A1 }\end{array}$} & 1 & 0,37 & 200 & 189 & 28 & 27 & 27 & 10,00 & 9,87 & 0,130 & 194 \\
\hline & & \multicolumn{11}{|c|}{$\begin{array}{l}\text { Второй автомобиль переезжает на М3 и выполняет плановый } \\
\text { объем перевозок для первого автомобиля }\end{array}$} \\
\hline & & 2 & $\begin{array}{l}0,37 \\
(0,61)\end{array}$ & 100 & 105 & 14 & 15 & 15 & 10,00 & 10,29 & - & 205 \\
\hline 2 & $\begin{array}{l}\text { А2Б2- } \\
\text { Б2А2 }\end{array}$ & 1 & 0,37 & 150 & 147 & 21 & 27 & 21 & 10,00 & 7,65 & 2,350 & 186 \\
\hline 3 & $\begin{array}{l}\text { А5Б6- } \\
\text { Б6А5 }\end{array}$ & \multicolumn{11}{|c|}{$\begin{array}{l}\text { Плановый объем перевозок для первого автомобиля выпол- } \\
\text { няет второй автомобиль, работающий на М1 }\end{array}$} \\
\hline \multirow[t]{3}{*}{4} & \multirow{3}{*}{$\begin{array}{l}\text { А4Б8- } \\
\text { Б8А4 }\end{array}$} & 1 & 0,45 & 200 & 154 & 28 & 22 & 22 & 10,00 & 9,74 & 0,260 & 218 \\
\hline & & \multicolumn{11}{|c|}{$\begin{array}{l}\text { Второй автомобиль переезжает на М10 и выполняет плано- } \\
\text { вый объем перевозок для первого автомобиля }\end{array}$} \\
\hline & & 2 & $\begin{array}{l}0,45 \\
(3,71) \\
\end{array}$ & 25 & 56 & 3 & 8 & 8 & 10,00 & 10,96 & - & 233 \\
\hline \multirow[t]{2}{*}{5} & \multirow{2}{*}{$\begin{array}{l}\text { А8Б11- } \\
\text { Б11А8 }\end{array}$} & 1 & 2,05 & 50 & 28 & 7 & 4 & 4 & 10,00 & 8,36 & 0,520 & 196 \\
\hline & & \multicolumn{11}{|c|}{$\begin{array}{l}\text { Плановый объем перевозок для второго автомобиля выполня- } \\
\text { ет третий автомобиль, работающий на М8 }\end{array}$} \\
\hline 6 & $\begin{array}{l}\text { А7Б12- } \\
\text { Б12A7 }\end{array}$ & 1 & 0,45 & 150 & 147 & 21 & 22 & 21 & 10,00 & 9,29 & 0,710 & 180 \\
\hline
\end{tabular}


Окончание табл. 2.

\begin{tabular}{|c|c|c|c|c|c|c|c|c|c|c|c|c|}
\hline \multirow[t]{7}{*}{7} & \multirow{7}{*}{ 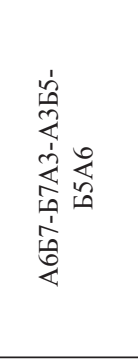 } & 1 & 2,18 & \multirow{5}{*}{150} & 28 & \multirow{5}{*}{21} & 4 & \multirow{2}{*}{$\begin{array}{l}4 \\
4\end{array}$} & \multirow{2}{*}{$\frac{10,00}{10,00}$} & \multirow{2}{*}{8,56} & \multirow{2}{*}{$\frac{1,440}{1,440}$} & 200 \\
\hline & & 2 & 2,18 & & \multirow{2}{*}{\begin{tabular}{|l|}
28 \\
28
\end{tabular}} & & 4 & & & & & 00 \\
\hline & & 3 & 2,18 & & & & 4 & 4 & 9,935 & 8,56 & 1,375 & 200 \\
\hline & & 4 & 2,18 & & 28 & & 4 & 4 & 9,935 & 8,56 & 1,375 & 200 \\
\hline & & 5 & 2,18 & & 28 & & 4 & 4 & 9,870 & 8,56 & 1,310 & 200 \\
\hline & & & сой ав & $\mathrm{OM}$ & 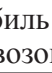 & Pe & & & $\begin{array}{l}\text { М9 и в } \\
\text { автомо }\end{array}$ & Іполн & т плаң & \\
\hline & & 6 & $\begin{array}{l}2,18 \\
(3,68)\end{array}$ & 100 & 21 & 14 & 3 & 3 & 9,870 & 9,70 & 0,170 & 212 \\
\hline \multirow[t]{4}{*}{8} & \multirow{4}{*}{ 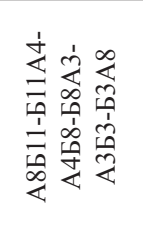 } & 1 & 2,91 & \multirow[b]{2}{*}{50} & 21 & \multirow[b]{2}{*}{7} & 5 & 3 & 9,935 & 8,65 & 1,285 & 190 \\
\hline & & 2 & 2,91 & & 21 & & 3 & 3 & 9,935 & 8,65 & 1,285 & 190 \\
\hline & & \multicolumn{11}{|c|}{$\begin{array}{l}\text { Третий автомобиль переезжает на М5 и выполняет плановый } \\
\text { объем перевозок для второго автомобиля }\end{array}$} \\
\hline & & 3 & $\begin{array}{l}2,91 \\
(2,05)\end{array}$ & 50 & 28 & 7 & 4 & 4 & 9,870 & 10,26 & - & 161 \\
\hline \multirow[t]{7}{*}{9} & \multirow{7}{*}{ 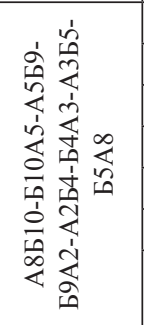 } & 1 & 3,68 & \multirow{6}{*}{100} & 14 & \multirow{6}{*}{14} & & 2 & 9,870 & 7,12 & 2,750 & 162 \\
\hline & & 2 & 3,68 & & 14 & & 2 & 2 & 9,805 & 7,12 & 2,685 & 162 \\
\hline & & 3 & 3,68 & & 14 & & 2 & 2 & 9,805 & 7,12 & 2,685 & 162 \\
\hline & & 4 & 3,68 & & 14 & & 2 & 2 & 9,740 & 7,12 & 2,620 & 162 \\
\hline & & 5 & 3,68 & & 14 & & 2 & 2 & 9,740 & 7,12 & 2,620 & 162 \\
\hline & & 6 & 3,68 & & 14 & & 2 & 2 & 9,675 & 7,12 & 2,555 & 162 \\
\hline & & \multicolumn{11}{|c|}{$\begin{array}{l}\text { Плановый объем перевозок для седьмого автомобиля выпол- } \\
\text { няет шестой автомобиль, работающий на М7 }\end{array}$} \\
\hline \multirow[t]{2}{*}{10} & \multirow{2}{*}{ 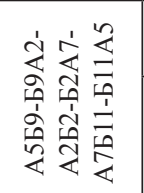 } & & $\begin{array}{l}\text { новый } \\
\text { г второі }\end{array}$ & ббъен & и пер & & & 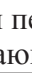 & $\begin{array}{l}\text { вого ан } \\
\text { ий на } 1\end{array}$ & 4 & гя вып & \\
\hline & & 2 & 3,71 & 25 & 7 & 1 & 2 & 1 & 9,935 & 2,79 & 7,145 & 87 \\
\hline 11 & 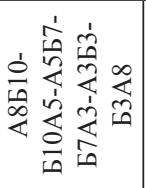 & 1 & 3,15 & 25 & 21 & 3 & 3 & 3 & 9,610 & 9,37 & 0,24 & 208 \\
\hline 12 & 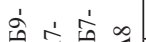 & 1 & 5,58 & & & 3 & 1 & 1 & 9,610 & 5,62 & 3,99 & 121 \\
\hline & $\begin{array}{l}\bar{n} \\
4\end{array}$ & 2 & 5,58 & 25 & 7 & 3 & 1 & 1 & 9,545 & 5,62 & 3,925 & 121 \\
\hline & 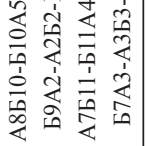 & 3 & 5,58 & & & 3 & 1 & 1 & 9,545 & 5,62 & 3,925 & 121 \\
\hline
\end{tabular}




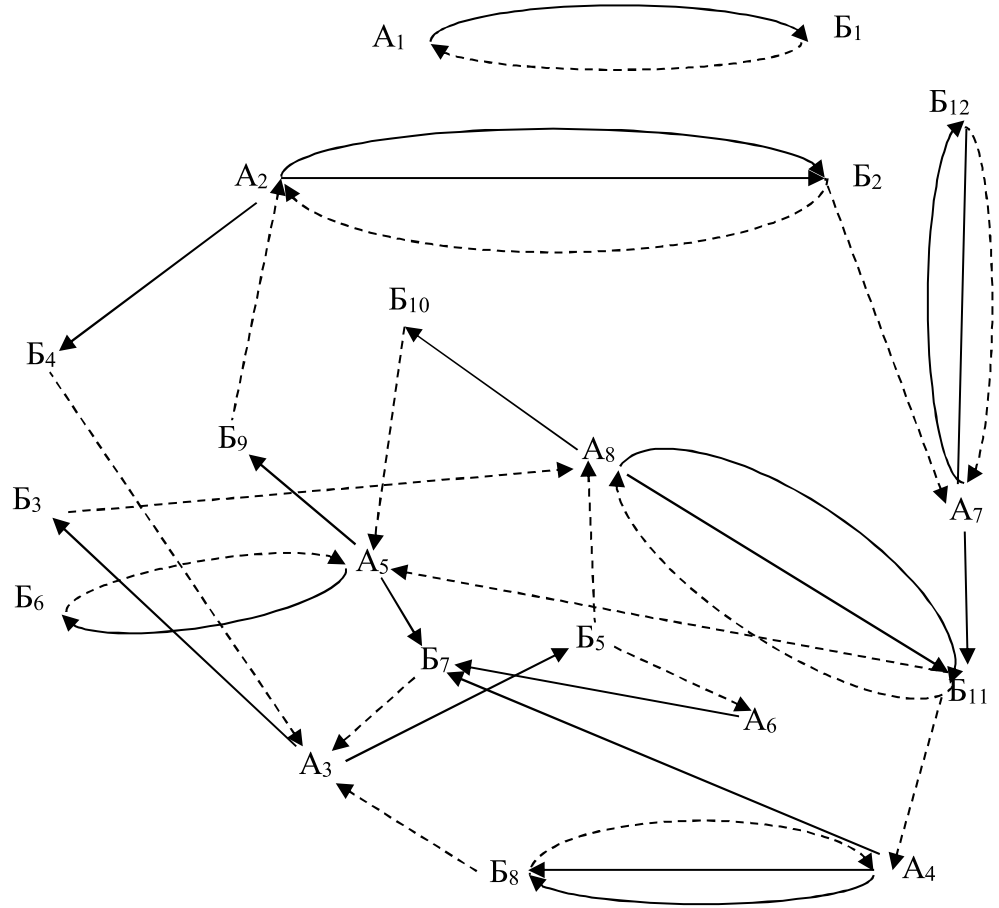

Рис. 4. Транспортные схемы доставки грузов, спроектированные по предлагаемой методике

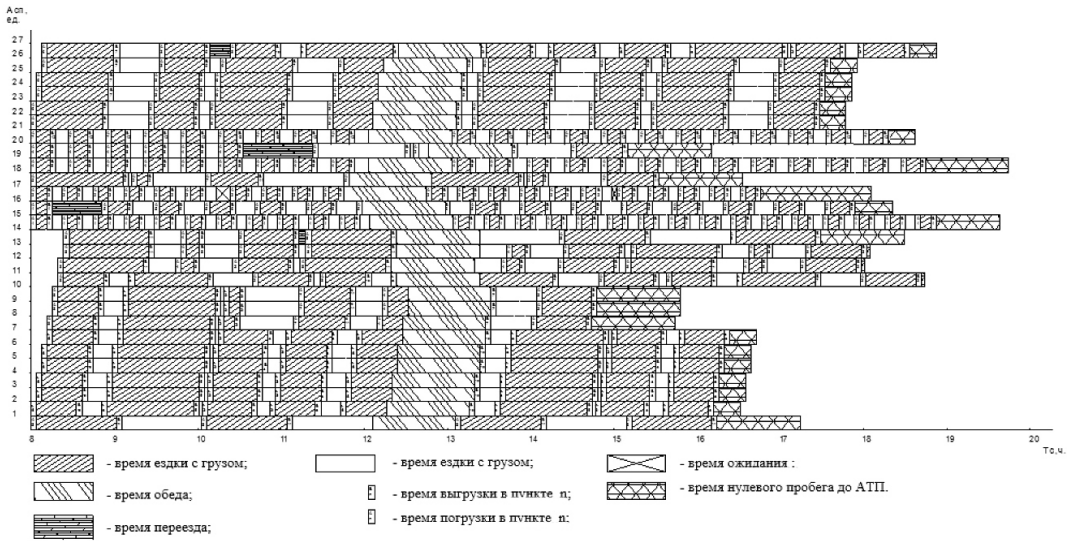

Рис. 5. График работы автомобилей по предложенной методике 


\section{Обсуждение и заключения}

В результате реализации расчетов по представленной методике получили оптимальный план перевозок, отвечающий требованиям грузовладельцев. В дальнейшем необходимо разработать методику управления работой автомобиля в спроектированных транспортных системах доставки грузов. В результате моделирования транспортного процесса получено, что взаимодействие через общие посты разгрузки, погрузки, вызвало дополнительные потери времени в ожидании автомобилей, учет которых необходим при планировании. Предложенный подход к оперативному планированию дает возможность: установить научно обоснованные нормативные задания для транспортных средств, рассчитать производительность, объем перевозок, потребность в транспортных средствах и определить занятость по времени грузовых постов.

Опровергнуто утверждение, что в совокупности транспортных систем отсутствуют маршруты, а есть только “грузовые направления". На самом деле грузовой автомобиль после всех расчетов имеет плановое задание (очередность исполнения операций транспортного процесса), т.е. сформированы маршруты перевозок, исполнение которых осуществляется в определенной транспортной системе или их совокупностей (если переезд из системы в систему для данного автомобиля возможен). В связи с этим, одни автомобили могут работать в одной транспортной системе, назовем ее “базовой”, другие автомобили этой же системы могут работать в других транспортных системах, при выполнении условий переезда. На основе расчетов можно определить возможность выполнения транспортных заданий перевозок грузов и в дальнейшем применить результаты расчетов для принятия оперативных управленческих решений при возникновении сбойных ситуаций. Анализ результатов применения предложенной методики при различных условиях перевозки грузов показал, что в городских условиях эксплуатации обслуживание поставщиков и потребителей грузов, осуществляется в интегрированной автотранспортной системе. В 
нашем случае в интегрированную систему объединяются одна малая система и одна совокупность средних систем.

Анализ результатов решения транспортной задачи любым из известных методов линейного программирования позволяет получить оптимальное решение по выбранному критерию, ошибки в расчетах лежат не в области решения данной модели, а в области дальнейшей расшифровки полученного решения. Доказано, что при решении задачи маршрутизации перевозок грузов может проектироваться весь спектр транспортных систем, от изолированных от других транспортных системы до совокупности (интегрированных транспортных систем). Новшества, предложенные в методику оперативного планирования грузовых автомобилей в спроектированных системах позволяют получить научно обоснованное плановое задание на перевозку грузов.

\section{Сиисок литературы}

1. Николин В.И. Проектирование автотранспортных систем доставки грузов / В.И. Николин, С.М. Мочалин, Е.Е. Витвицкий, И.В. Николин; Под ред. проф. В.И. Николина. Омск: Изд-во СибАДИ, 2001. 184 c.

2. Трофимов Б.С. Новые результаты решения транспортной задачи / Б.С. Трофимов, Е.Е. Витвицкий // Автотранспортное предприятие. 2012. №7. C. 49-52.

3. Афанасьев Л.Л. Единая транспортная система и автомобильные перевозки: учебник для вузов / Л.Л. Афанасьев, Н.Б. Островский, С.М. Цукерберг. М.: Транспорт, 1984. 333 с.

4. Мочалин М.С. Анализ практики оперативного планирования перевозочной деятельности в автотранспортной системе доставки грузов // Материалы международной 65-й научно-практической конференции ФГБОУ ВПО СибАДИ «Ориентированные фундаментальные и прикладные исследования - основа модернизации и инновационного развития архитектурно-строительного и дорожно-транспортного комплексов России». Омск: Издательство СибАДИ, 2011. С. 93-97. 
5. Мочалин М.С. Эффективность применения методов решения транспортной задачи маршрутизации перевозок грузов автотранспортом // Материалы международной 66-й научно-практической конференции ФГБОУ ВПО СибАДИ «Ориентированные фундаментальные и прикладные исследования - основа модернизации и инновационного развития архитектурно-строительного и дорожно-транспортного комплексов России». Кн. 2. Омск: Издательство СибАДИ, 2012. С. 346-348.

6. Мочалин М.С. Анализ практики применения ЭММ при решении задач маршрутизации перевозок грузов // Научные труды молодых ученых, аспирантов и студентов, межвузовский сборник. Вып. 9. Омск: Издательство СибАДИ, 2012. С. 331-338.

7. Мочалин М.С., Певнев Н.Г. Обоснование необходимости логистического управления в транспортных системах доставки грузов. Логистика-евразийский мост: материалы 11-ой Международной конференции / Краснояр.гос.аграр.ун-т-ч.1. Красноярск, 2016. 436 с.

8. Мочалин М.С., Певнев Н.Г. и др. Актуальные вопросы научных исследований XXI века. Кол.монография [Электронный ресурс], СибАДИ, Омск, 2015. 1200 с.

9. Геронимус Б.Л. Экономико-математические методы в планировании на автомобильных транспорте. М.: Транспорт, 1982. 190 с.

10. Кожин А.П., Мезенцев В.Н. Математические методы в планировании и управлении грузовыми автомобильными перевозками. М.: Транспорт, 1994. 304 с.

11. Кофман А., Анри-Лабрадер А. Методы и модели исследования операций. Целочисленное программирование. М.: Мир, 1977. $432 \mathrm{c}$.

12.Горев А.Э. Грузовые автомобильные перевозки: учеб. Пособие. М.: Академия, 2008.

13. Войтенков С.С. Совершенствование оперативного планирования перевозок грузов помашинными отправками в городах: Автореф. дис... канд. техн. наук: 05.22.10. Иркутск, 2011. 20 с.

14. Таха Х.А. Введение в исследование операций. 7-е издание. Пер. с англ. Москва: Вильямс, 2005. 912 с. 
15.Конвей Р.В. Теория расписаний: учебное пособие / Р.В. Конвей, У.Л. Максвелл, Л.В. Миллер. М.: Наука, 1975. 359 с.

\section{References}

1. Nikolin V.I., Mochalin S.M., Vitvitsky E.E., Nikolin I.V. Proektirovanie avtotransportnykh sistem dostavki gruzov [Design of motor transportation systems of cargo delivery]; ed. prof. V.I. Nikolin. Omsk: Izd-vo SibADI, 2001. 184 p.

2. Trofimov B.S., Vitvitsky E.E. Avtotransportnoe predpriyatie. 2012. №7, pp. 49-52.

3. Afanas'ev L.L., Ostrovskiy N.B., Tsukerberg S.M. Edinaya transportnaya sistema i avtomobil'nye perevozki [Unified transport system and road transport]. M.: Transport, 1984. 333 p.

4. Mochalin M.S. Materialy mezhdunarodnoy 65-y nauchno-prakticheskoy konferentsii FGBOU VPO SibADI «Orientirovannye fundamental'nye i prikladnye issledovaniya - osnova modernizatsii i innovatsionnogo razvitiya arkhitekturno-stroitel'nogo i dorozhno-transportnogo kompleksov Rossii» [Materials of the international 65th scientific-practical conference of the FSBEI HPE SibADI "Oriented fundamental and applied research - the basis of modernization and innovative development of architectural, construction and road transport complexes of Russia"]. Omsk: Izdatel'stvo SibADI, 2011, pp. 93-97.

5. Mochalin M.S. Materialy mezhdunarodnoy 66-y nauchno-prakticheskoy konferentsii FGBOU VPO SibADI «Orientirovannye fundamental'nye i prikladnye issledovaniya - osnova modernizatsii i innovatsionnogo razvitiya arkhitekturno-stroitel'nogo i dorozhno-transportnogo kompleksov Rossii» [Materials of the international 66th scientific-practical conference of the FSBEI HPE SibADI "Oriented fundamental and applied research - the basis of modernization and innovative development of architectural, construction and road transport complexes of Russia"]. Book 2. Omsk: Izdatel'stvo SibADI, 2012, pp. 346-348.

6. Mochalin M.S. Nauchnye trudy molodykh uchenykh, aspirantov $i$ studentov, mezhvuzovskiy sbornik [Scientific works of young scientists, graduate students and students, inter-university collection]. Issue 9. Omsk: Izdatel'stvo SibADI, 2012, pp. 331-338. 
7. Mochalin M.S., Pevnev N.G. Logistika-evraziyskiy most: materialy 11oy Mezhdunarodnoy konferentsii [Logistics-Eurasian Bridge: Materials of the 11th International Conference]/ Krasnoyar.gos.agrar.un-t-ch.1. Krasnoyarsk, 2016. 436 p.

8. Mochalin M.S., Pevnev N.G. et al. Aktual'nye voprosy nauchnykh issledovaniy XXI veka. Kol.monografiya [Actual issues of scientific research of the XXI century], SibADI, Omsk, 2015. 1200 p.

9. Geronimus B.L. Ekonomiko-matematicheskie metody v planirovanii na avtomobil'nykh transporte [Economic and mathematical methods in planning on automobile transport]. M.: Transport, 1982. $190 \mathrm{p}$.

10. Kozhin A.P., Mezentsev V.N. Matematicheskie metody v planirovanii i upravlenii gruzovymi avtomobil'nymi perevozkami [Mathematical methods in the planning and management of road freight transport]. M.: Transport, 1994. 304 p.

11. Kofman A., Anri-Labrader A. Metody i modeli issledovaniya operatsiy. Tselochislennoe programmirovanie [Methods and models of operations research. Integer programming]. M.: Mir, 1977. 432 p.

12. Gorev A.E. Gruzovye avtomobil'nye perevozki: ucheb. Posobie [Freight road transport: textbook]. M.: Akademiya, 2008.

13. Voytenkov S.S. Sovershenstvovanie operativnogo planirovaniya perevozok gruzov pomashinnymi otpravkami v gorodakh [Improving the operational planning of transportation of goods by truck dispatches in cities]. Irkutsk, 2011. 20 p.

14. Takha Kh.A. Vvedenie v issledovanie operatsiy [Introduction to operations research]. Moskva: Vil'yams, 2005. 912 p.

15. Konvey R.V. Teoriya raspisaniy [Schedule Theory] / R.V. Konvey, U.L. Maksvell, L.V. Miller. M.: Nauka, 1975. 359 p.

\section{ДАННЫЕ ОБ АВТОРАХ}

Мочалин Михаил Сергеевич, соискатель кафедры «Логистика» Сибирский государственный автомобильно-дорожный университет (СибАДИ)

пр. Мира, 5, Омск, Омская обл., 644080, Российская Федерачия

Mochalin_ms@mail.ru 
Кухарев Егор Александрович, магистрант кафедры «Логистика» Сибирский государственный автомобильно-дорожньй университет (СибАДИ)

пр. Мира, 5, Омск, Омская обл., 644080, Российская Федераиия

egortang95@mail.ru

\section{DATA ABOUT THE AUTHORS}

Mochalin Mikhail Sergeevich, job seeker of the department "Logistics" Siberian State Automobile and Highway University (SibADI) 5, Mira Ave., Omsk, Omsk Region, 644080, Russian Federation Mochalin_ms@mail.ru

Kukharev Egor Aleksandrovich, master student of the department "Logistics"

Siberian State Automobile and Highway University (SibADI) 5, Mira Ave., Omsk, Omsk Region, 644080, Russian Federation egortang95@mail.ru

SPIN-code: 1896-0793

ORCID: 0000-0003-4897-0674

ResearcherID: 2914640 